\title{
Geographical variation in egg size of the Great Tit Parus major: a new perspective
}

\author{
SILVIO I. ENCABO, EMILIO BARBA,* JOSE A. GIL-DELGADO \& JUAN S. MONRÓS \\ Instituto 'Cavanilles' de Biodiversidad y Biología Evolutiva, Universidad de Valencia, \\ Apartado Oficial 2085, E-46071 Valencia, Spain
}

\begin{abstract}
A recent study on geographical variation in egg size of Great Tits Parus major concluded that: (1) mean egg size tended to increase with increasing latitude; and (2) mean egg size was positively correlated with mean clutch size. Including new data on both egg and clutch size, we reanalysed the relationships between egg size, clutch size and latitude, and investigated the possible effects of habitat type, female body size and egg shape on these relationships. We found that (1) egg volume showed minimum values around $51^{\circ} \mathrm{N}$, increasing both north and southwards; (2) female body size increased linearly with increasing latitude; (3) female body size was positively correlated with egg breadth, but not with egg length or egg volume; (4) the sphericity index of the eggs (breadth to length ratio) was largest at medium latitudes, and eggs were more elongated towards the north and the south; (5) the relationship between clutch size and latitude was curvilinear, with the largest clutch sizes at intermediate latitudes; (6) egg size was not correlated with clutch size when the complete latitudinal range was considered, but egg size was negatively correlated with clutch size between 40 and $51^{\circ} \mathrm{N}$; and (7) egg size did not differ among habitat types. We suggest that female body size (which probably limits egg breadth), and the pressure for producing large eggs (which in turn increases the reproductive success) are the main determinants of geographical variation in egg size and shape. Populations of small-bodied Great Tits seem to escape from the limits of their size, producing relatively elongated eggs, so that from a certain latitude southwards, egg volume does not decrease in spite of a decrease in female body size. Moreover, the negative relationship between egg and clutch size at low latitudes suggests that energetic trade-offs may also contribute to determine egg size in the south.
\end{abstract}

It is known that egg size can affect the reproductive output of birds, especially influencing chick survival during the first days of life (reviewed in Williams 1994). Hatchability of the eggs may also be affected by their size, especially under severe weather conditions (Järvinen \& Väisänen 1983, Nilsson \& Svensson 1993). If egg size has fitness consequences, egg size differences among populations should be indicators of different pressures and limitations across the distribution range of the species. However, geographical variation in egg size, and the factors that might affect it, have received little attention to date.

In an analysis of the geographical variation of egg size in the Great Tit Parus major, Hõrak et al. (1995) concluded that: (1) mean egg size tended to increase

${ }^{*}$ Corresponding author.

Email: barba@uv.es with increasing latitude; and (2) mean egg size was positively correlated with mean clutch size. On the first point, they argued that the positive correlation between egg size and latitude could be caused by an increase in female body size towards the north, bigger females producing larger eggs. On the second point, they offered two explanations for the positive relationship between egg and clutch size: (a) it could be caused by food limitation on both egg and clutch size, so that populations occupying better habitats are able to lay larger clutches of larger eggs; or (b) it could arise as a by-product of an independent increase of egg size and clutch size with latitude.

Our own work on a Mediterranean Great Tit population (e.g. Barba 1992, Barba et al. 1995, Belda et al. 1998), as well as recent analyses of geographical trends in breeding traits (Sanz 1998), allows a reconsideration of the above explanations. As Hõrak et al. 
(1995) assumed, the body size (measured as wing length) of female Great Tits increases with latitude (Snow 1954, Barba 1992). As female body size and, specifically, pelvic width, could limit egg breadth, we might expect a correlation between female body size and egg breadth. Furthermore, we might expect egg length to be less severely limited than egg breadth. In fact, egg length is usually more variable than egg breadth (e.g. Järvinen \& Väisänen 1983, Hendricks 1991), and female body size is indeed usually correlated more strongly with egg breadth than with egg length (e.g. Ojanen et al. 1979). Therefore, changes in egg shape may allow populations of relatively small birds to escape from the constraints of their body size by producing relatively large, more elongated, eggs. Most populations included in the analysis of Horak et al. (1995) were north of $47^{\circ} \mathrm{N}$. The addition of information on egg size from southern (smaller-bodied) populations, along with an analysis of latitudinal trends in egg shape and female body size, might be revealing.

The second point raised by Hõrak et al. (1995) was the positive relationship between egg size and clutch size. Their first explanation for this relationship was that both egg and clutch size could be positively related with food availability. Sanz (1998) has shown that habitat type, as an indicator of food availability, significantly affects clutch size. We assess Hõrak et al.'s (1995) first hypothesis by looking for a similar relationship between habitat type and egg size in the populations for which this information is available.

The second explanation proposed by Horak et al. (1995) was that the positive relationship between egg and clutch size could be a by-product of an independent increase in both variables with latitude. Recent reviews show that clutch size increases with latitude but reaches a plateau at higher latitudes (Barba 1992, Sanz 1998). Therefore, Hõrak et al.'s (1995) second hypothesis would be supported if the relationships between egg size and latitude, and clutch size and latitude have the same (curvilinear) shape, but rejected if the shape of these relationships differs.

This paper aims to clarify the relationships between egg size and the main factors proposed to affect it at the between-population level: female body size, latitude, habitat type and mean clutch size. We will also investigate the role of egg shape variation in these relationships.

\section{METHODS}

The main analyses presented here were based on data on egg dimensions from 38 Great Tit popula- tions across Europe, ranging from 40 to $69^{\circ} \mathrm{N}$ (Appendix 1). From a larger data set we excluded data on egg dimensions compiled in general publications (e.g. atlases) for which exact geographical origins were not clear, covered very large areas, or were collected in an unsystematic way (see Barba 1992 for references). We also excluded data from a Finnish population (Eeva \& Lehikonen 1995), since most measurements were taken from eggs that failed to hatch. We calculated a mean egg volume of $1.60 \mathrm{~cm}^{3}$ for this Finnish population, a rather low value (compare with values in Appendix 1). Järvinen and Väisänen (1983) found that small eggs do not hatch well in northern latitudes, so the sample might be biased towards small eggs.

Three equations for calculating egg volume from linear dimensions can be found in the literature (Ojanen et al. 1978, Hoyt 1979, Van Noordwijk et al. 1981). Since these produce different results (though the absolute value is irrelevant for this study), we calculated the egg volume using Hoyt's (1979) equation for all populations presented here: $V=\pi / 6 L B^{2}$, where $V$ is egg volume (in $\mathrm{mm}^{3}$ ), $L$ is egg length and $B$ is egg breadth (both in $\mathrm{mm}$ ). This implied the recalculation of egg volumes in those cases where they were originally calculated using any other method. If not given in the original source, the sphericity index was calculated by us as $B / L$ (e.g. Encabo et al. 2001 a) using the values of breadth and length presented in Appendix 1.

When a mean length, breadth and volume were given for a population, these values were taken. Most studies used clutch means, but some used individual eggs as sample units; however, using individual eggs or clutch means does not change the mean values appreciably (e.g. Haftorn 1985, Barba 1992). In our data set from Sagunto, egg volume was approximately normally distributed using either clutch means $(Z=0.61, P=0.86)$ or individual eggs $(Z=$ $0.94, P=0.34$; Kolmogorov-Smirnov tests), so both clutch means and means across individual eggs adequately reflected the population mean. Some papers only gave the annual means for egg dimensions, so the average of annual means was calculated for our analyses, sample size being the number of years in these cases. Mean egg volumes are fairly constant in different years (e.g. Järvinen 1991, Encabo et al. $2001 b)$. Therefore, we feel that the way of calculating the population mean is unlikely to affect the results.

Most papers checked gave clutch size, latitude and type of habitat along with egg size. If not, other 
published studies from the same populations were consulted (details in Appendix 1). When a mean clutch size was given for a population, this value was taken; the average of annual means was used if a total was not given. In the few cases where no exact information on the latitude of the study site was found, we used maps to estimate it. Habitats were coded as deciduous, coniferous and mixed (deciduousconiferous). Urban and suburban habitats, and orange plantations, were not included in the analyses of habitat effects since sample sizes were too small.

We reviewed the literature for estimates of female body size. We selected wing length as an index of body size, since this was the parameter most frequently given and because Gosler et al. (1998) showed that this is a good measure of body size in this species. For the Sagunto population, we used data from all the females ringed during 1992-1999. Wing length was measured to the nearest $0.5 \mathrm{~mm}$ as the maximum length of the wing (Svensson 1996) using a ruler with a zero stop. We used measurements taken at the first capture of breeding individuals.

Data points used in the regression analyses were based on very different sample sizes. As the shape and significance of the regressions were crucial for our conclusions, we used weighted regression analyses. We used sample sizes (number of clutches) as the weighting factor, assuming that the precision of the estimate increased with sample size. More adequate measures of the precision, as standard deviations or errors, could not be used since they were calculated in different ways for different populations, or were not available at all. The exact weighting function used was $\left(1 / n^{x}\right)$, where $n$ is the sample size and $x$ is a value between -2 and 2 . The power value $x$ was selected so that the log-likelihood function was maximized in each case, and it is given for each regression performed. For those cases where sample sizes were numbers of eggs, and the exact number of clutches used was not given, we estimated it by dividing the number of eggs measured by the mean clutch size of the population. The number of clutches (actual or estimated) used for weighting each population is detailed in Appendix 1.

We tested for non-linear relationships by including the square of the predictor variable in the analyses. We performed stepwise polynomial regressions, using a forward selection procedure. We first fitted a linear regression, and then fitted a quadratic equation. To determine whether the addition of the quadratic term significantly improved the accuracy of the prediction of $Y$ values we used $t$-tests. Analyses were performed using the SPSS/PC+ statistical package (SPSS Inc. 1998).

\section{RESULTS}

We found a significant, curvilinear relationship between egg volume and latitude, with a minimum egg volume around $51^{\circ} \mathrm{N}$ and an increase in egg volume north and southwards (Fig. la). Because the significance of the quadratic term may be based on the large eggs at high latitudes, rather than on an actual increase in egg size in southern populations, we tested directly whether egg volume really increased at low latitudes. This was done by omitting data from latitudes higher than $51^{\circ} \mathrm{N}$ and testing again for an effect of latitude. The restricted data set showed that there was an increase in egg volume from medium to low latitudes (weighted regression, $x=0, V=1.9812$ $-6.96 \times 10^{-3} \times$ lat; $R^{2}=0.33, F_{1,18}=8.96, P=0.008$ ).

Mean egg breadth increased linearly with latitude (Fig. 1b), but the length of the eggs followed a concave trend, with longer eggs in the north and south of the species' geographical range, and shorter eggs at medium latitudes (Fig. 1c). As a consequence, the sphericity index was largest at medium latitudes, and eggs were more elongated towards the north and the south (Fig. 1d).

We checked all the above relationships removing the single high-latitude point, since it seems to have a large weight in the regressions. The results did not differ for egg volume, egg breadth and egg shape, the quadratic factor being significant for egg volume and shape. However, the relationship between egg length and latitude lost significance (weighted regression, $x=0, F_{2,19}=2.89, P=0.08$ ), so this relationship must be considered with caution.

Female wing length increased significantly with latitude (Fig. 2). For the 11 populations for which both wing length and egg dimensions were available, egg breadth was positively related to female wing length (Fig. 3), while egg length $\left(F_{19}=0.10, P=0.75\right)$ and egg volume $\left(F_{1,9}=4.59, P=0.06\right)$ were not.

We found no significant relationship between mean egg volume and mean clutch size $\left(F_{1,36}=0.84\right.$, $P=0.36)$. The relationship between clutch size and latitude, using only the populations for which both egg and clutch sizes were available, was curvilinear, with the largest clutches at intermediate latitudes (Fig. 4). Sanz (1998) reached the same conclusion with a larger data set. As there was a relationship between egg volume and latitude, we controlled for differences in latitude by using the residuals of the weighted regression of egg volume against latitude 

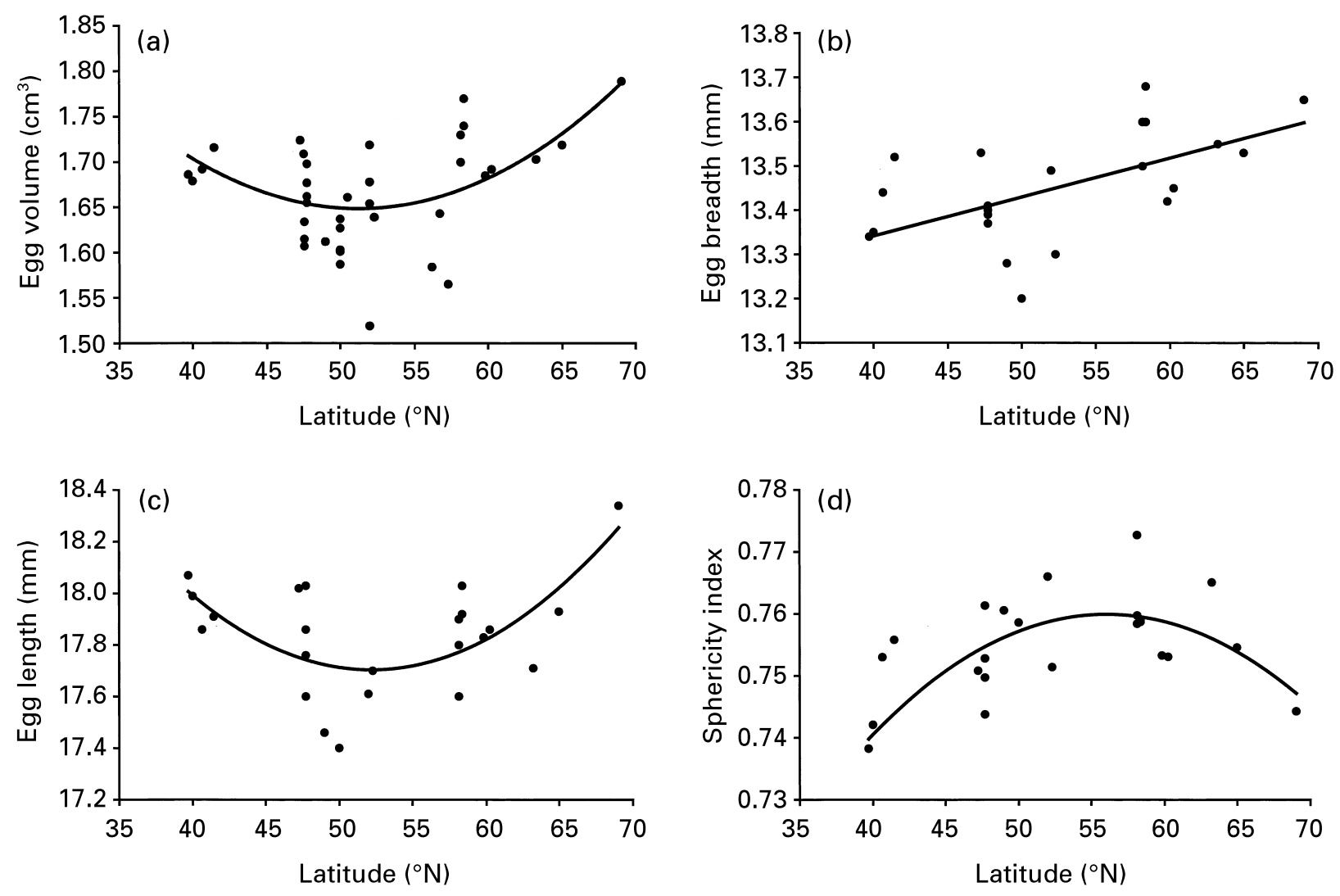

Figure 1. Latitudinal trends in egg dimensions of Great Tits (weighted regressions). (a) Volume; equation fitted was $V=2.7953-$ $0.0448 \times$ lat $+4.37 \times 10^{-4} \times$ lat $^{2}\left(x=0.5, R^{2}=0.32, F_{2,35}=8.17, P=0.001\right) ;($ b $)$ breadth; equation fitted was $B=12.9870+0.0089 \times$ lat $\left(x=0.5, R^{2}=0.36, F_{1,21}=12.05, P=0.002\right)$; (c) length; equation fitted was $L=22.9928-0.2026 \times$ lat $^{2}+1.94 \times 10^{-3} \times$ lat $^{2}(x=0$,

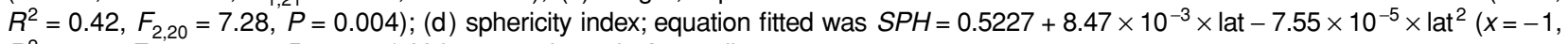
$\left.R^{2}=0.80, F_{2,20}=39.31, P<0.001\right)$. Values are shown in Appendix 1.

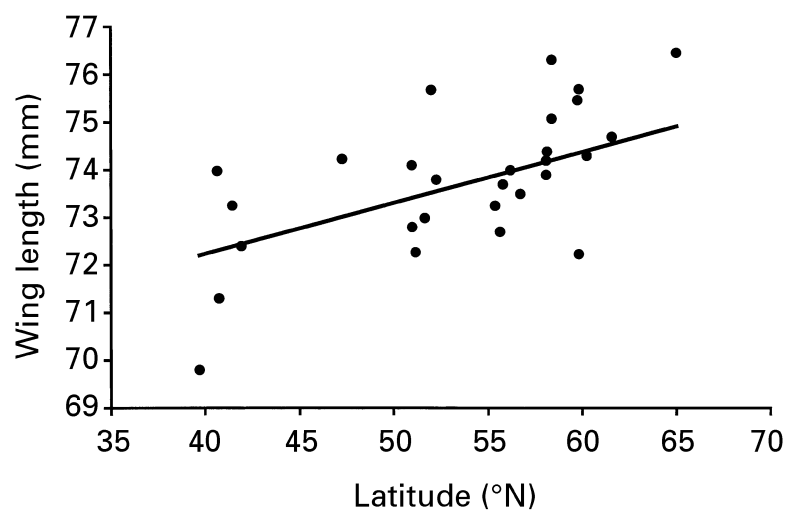

Figure 2. Latitudinal trend in female mean wing length $(W L)$ (weighted regression, $x=0.5): W L=67.94+0.11 \times$ lat $\left(R^{2}=0.35\right.$, $\left.F_{1,26}=14.07, P<0.001\right)$. Values are shown in Appendix 2.

(see Fig. 1a). Residual egg volume was not related to clutch size $\left(F_{1,36}=2.93, P=0.10\right)$. Since the trend in egg volume changed at $51^{\circ} \mathrm{N}$, we tested independently whether egg volume was related to clutch size above

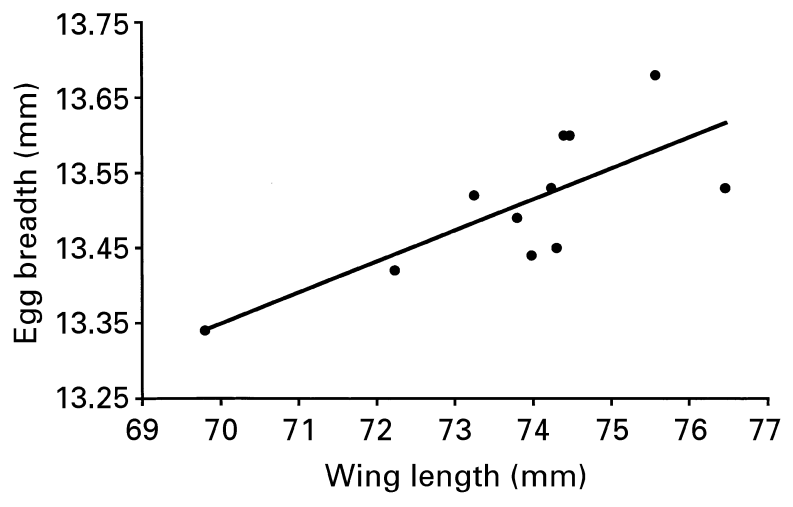

Figure 3. Relationship between egg breadth and female wing length: $B=10.45+0.0414 \times W L\left(R^{2}=0.56, F_{1,9}=11.60, P=\right.$ 0.008).

and below this latitude. There was no relationship between egg volume and clutch size above $51^{\circ} \mathrm{N}$ $\left(F_{1,16}=3.52, P=0.079\right)$, but egg volume increased significantly with decreasing clutch size (CS) below 


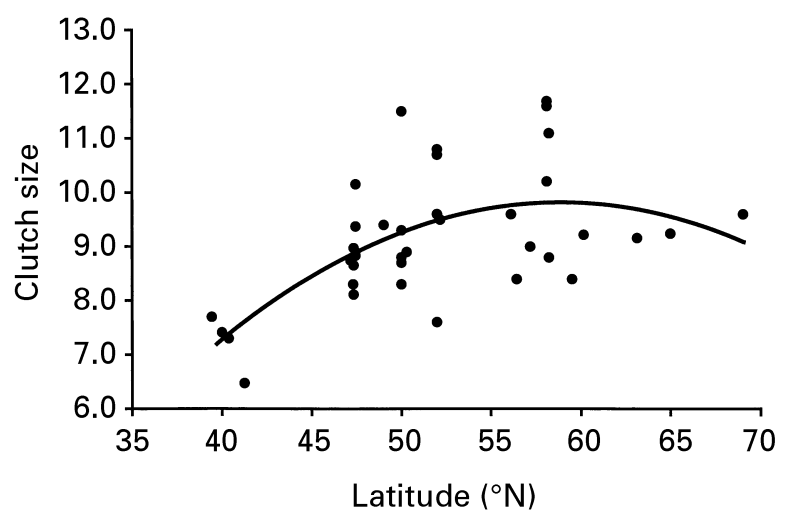

Figure 4. Latitudinal trend in mean clutch size (CS) (weighted regression, $x=0)$ : $C S=-15.959+0.877 \times$ lat $-7.46 \times 10^{-3} \times$ lat $^{2}$ $\left(R^{2}=0.38, F_{2,35}=10.50, P<0.001\right)$. Values are shown in Appendix 1 .

this latitude $\left(V=1.82-1.95 \times 10^{-2} \times \mathrm{CS}, R^{2}=0.24\right.$, $P=0.028$ ).

Egg volume did not differ significantly between deciduous ( $\left.1.68 \mathrm{~cm}^{3}, \mathrm{sd}= \pm 0.05, n=14\right)$, mixed $\left(1.65 \mathrm{~cm}^{3}, \mathrm{sd}= \pm 0.06, n=12\right)$ and coniferous $\left(1.69 \mathrm{~cm}^{3}\right.$, $\mathrm{sd}= \pm 0.03, n=5$ ) habitats (ANOvA, $F_{2,28}=0.97, P=$ 0.39 ). Including latitude and latitude squared as covariates in the analysis, the factor habitat was not significant either (ANCOVA; model, $F_{4,26}=4.44$, $P=0.007$; factor habitat, $F_{2,26}=1.47, P=0.25$; covariate latitude, $F_{1,26}=8.00, P=0.009$; covariate latitude squared, $\left.F_{1,26}=9.15, P=0.006\right)$.

\section{DISCUSSION}

The results of our analyses do not support the two main conclusions on egg size variation reached by Hõrak et al. (1995). First, the relationship between egg size and latitude is not linear, but curvilinear, with minimum values around $51^{\circ} \mathrm{N}$ and increasing north and southwards. Secondly, we found no significant relationship between egg size and clutch size when the complete latitudinal range considered was analysed, but a negative relationship was found between 40 and $51^{\circ} \mathrm{N}$. Possible causes for these disagreements are discussed below.

\section{Latitude, female body size and egg shape}

The main argument of Hõrak et al. (1995) to explain the linear relationship between egg size and latitude was that female body size probably increased towards the north (following Bergmann's rule), and egg size would follow this increase. Since laying large eggs is advantageous, we might expect that the decrease in female body size towards the south would impose limits to egg size in southern populations. We have presented here evidence for the first part of the argument: female body size decreases towards the south, and this decrease is linear within the latitudinal range examined. However, the latitudinal variation in egg volume is not linear and, for the restricted data set available (11 populations), egg volume was not correlated with female body size.

A probable cause of this lack of relationship has been put forward above: female body size may impose a stronger limit on egg breadth than on egg length (see e.g. Järvinen \& Väisänen 1983). This idea is supported by our analyses, since (1) as in female body size, egg breadth increases linearly with latitude, while egg length is probably independent of latitude and (2) for a restricted data set, female body size is correlated with egg breadth, but not with egg volume. Combining the latitudinal variation of egg breadth, length and volume, it seems that egg breadth would be limited by female body size but, in southern populations, this limit on egg breadth is compensated by a relative lengthening of the eggs (lower sphericity index), so that egg volume does not decrease further. Moreover, an increase in egg volume from populations living at medium latitudes to those living more southerly was detected in the data set examined.

The ecological meaning of this latitudinal variation probably lies in the relationship between egg size and fitness: hatching failure rate is higher for small eggs, and hatchlings from small eggs have lower survival prospects (Järvinen \& Väisänen 1983, Nilsson \& Svensson 1993, Williams 1994). Given the within-population variability in egg size, populations with low mean egg size would have a high risk of producing eggs smaller than the minimum viable. Assuming the importance of laying large eggs, both the decrease in egg size from high to medium latitudes and the decrease from lower to medium ones need explanation.

The latitudinal variation from medium to high latitudes is better explained as an increase in egg volume with latitude. Part of this increase is explained by an increase in egg breadth, probably related to an increase in female body size. However, it is interesting that eggs are more elongated in the north (low sphericity index). Hatching from large eggs seems to be especially important in northern populations, where environmental conditions are more severe (Järvinen \& Väisänen 1983). In the north, producing 
large eggs, even at the cost of these being more elongated, seems more important than keeping a rounded shape to reduce the surface/volume ratio (and consequently heat loss). The relationship between hatchability and egg dimensions at northern latitudes would merit a more detailed study.

More difficult to explain is the increase in egg volume towards the south, via the elongation of the eggs. A hypothesis will be outlined below, taking into account the relationship between egg size and clutch size.

\section{Clutch size and habitat type}

Hõrak et al. (1995) looked for evidence of a trade-off between egg and clutch size but, in contrast, they found a positive relationship. We found no relationship when a greater latitudinal range was included in the analyses. However, when considering latitudes above and below $51^{\circ} \mathrm{N}$ separately (the point where the latitudinal trend in egg volume changed its sign), we found that mean egg volume was inversely correlated with clutch size at low latitudes, the relationship disappearing above $51^{\circ} \mathrm{N}$. Small clutch sizes are characteristic of Great Tit populations breeding in southern Europe (e.g. Belda et al. 1998), and inverse relationships between egg and clutch size are usually interpreted as the consequence of energetic tradeoffs (e.g. Soler \& Soler 1992). We think that the increase in mean egg size towards the south, from medium to low latitudes, could be interpreted in this context, so that southern populations, which lay smaller clutches, allocate more energy to increasing egg size. In contrast, above $51^{\circ} \mathrm{N}$, clutch size did not increase further (weighted regression, $x=0 ; F_{1,16}=$ $0.06, P=0.80$ ), while egg size showed a steep increase. As stated above, there are advantages in laying large eggs at high latitudes, so that additional energy available for breeding seems to be better invested in increasing egg size rather than clutch size.

We did not find a relationship between habitat type and egg size. Our sample size is small, but we could see no trend for producing larger eggs in the richest habitat, the deciduous forest. A direct comparison between different habitats located close to each other, and during the same breeding seasons, to eliminate confounding factors, would be interesting, but we are not aware of the existence of such data.

We would like to thank E.J. Belda, R. Dufva, P. Hõrak, and J.C. Senar for kindly providing unpublished data. We also thank P. Donald, M. de Renzi, J. Wilson and an anonymous referee for their comments on a previous draft. L. Arteaga, M. Marin and V. Vercher helped with the fieldwork in Sagunto. Two projects have contributed to the funding of the long-term Great Tit study in Sagunto: PS90-0266, DGICYT, Ministerio de Educación y Ciencia (19911993), and GV-2517/94, Generalitat Valenciana (19941996). Most of the costs of fieldwork for the other years were met by the authors.

\section{REFERENCES}

Alatalo, R.V., Gustafsson, L. \& Lundberg, A. 1984. Why do young passerine birds have shorter wings than older birds? Ibis 126: 410-415.

Báldi, A. \& Csörgö, T. 1993. Effect of habitat on the clutch size and egg dimensions of the Great Tit (Parus major). Aquila 100: 201-209.

Barba, E. 1992. Ecología de reproducción del Carbonero Común Parus major en el naranjal valenciano. Tesis doctoral, Universidad de Valencia.

Barba, E., Gil-Delgado, J.A. \& Monrós, J.S. 1995. The costs of being late: consequences of delaying great tit Parus major first clutches. J. Anim. Ecol. 64: 642-651.

Belda, E.J., Barba, E., Gil-Delgado, J.A., Iglesias, E.J., López, G.M. \& Monrós, J.S. 1998. Laying date and clutch size of Great Tits (Parus major) in the Mediterranean region: a comparison of four habitat types. J. Ornithol. 139: 269276.

Dhondt, A.A. \& Schillemans, J. 1983. Reproductive success of the Great Tit in relation to its territorial status. Anim. Behav. 31: 902-912.

Divis, T. \& Skalice, C. 1983. Prispevek nidobiologii nekterych nasich sykor Parus. Sbornik 5: 1-18.

Dufva, R. 1996. Blood parasites, health, reproductive success, and egg volume in female Great Tits Parus major. J. Avian Biol. 27: 83-87.

Ebenman, B. 1986. Sexual size dimorphism in the great tit Parus major in relation to the number of coexisting congeners. Oikos 47: 355-359.

Eeva, T. \& Lehikonen, E. 1995. Egg shell quality, clutch size and hatching success of the Great Tit (Parus major) and the Pied Flycatcher (Ficedula hypoleuca) in an air pollution gradient. Oecologia 102: 312-323.

Encabo, S.I., Barba, E., Gil-Delgado, J.A. \& Monrós, J.S. 2001a. Fitness consequences of egg shape variation: a study on two passerines and comments on the optimal egg shape model. Ornis Fenn. 78: 83-92.

Encabo, S.I., Monrós, J.S. \& Barba, E. 2001b. Egg size variation in a Mediterranean Great Tit Parus major population. Ardeola 48: 63-70.

Flegg, J.J. \& Cox, C.J. 1977. Morphometric studies of a population of Blue and Great Tits. Ring. Migr. 1: 135-140.

Fraticelli, F. \& Ruvolo, V. 1985. Dati preliminari sulla biometria di una popolazione mediterranea di cinciallegra (Parus major). Atti III Conv. Ital. Orn. 74-75.

Fusco, L., Scebba, S., Lancini, M. \& Milone, M. 1991. Biologia riproduttiva e morfologia di cinciallegra (Parus major) in un'isola del mediterraneo. Boll. Soc. Nat. NA 98-99: 91106.

Gosler, A.G., Greenwood, J.J.D., Baker, J.K. \& Davidson, N. 1998. Biometric determination of body size and condition in 
passerines: a report to the British Ringing Committee. Bird Study 45: 92-103.

Haftorn, S. 1976. Variation in body weight, wing length and tail length in the Great Tit Parus major. Norw. J. Zool. 24: 241271.

Haftorn, S. 1985. Variations in clutch size and egg dimensions of the Great Tit Parus major. Fauna norv. Series $C$, Cinclus 8: $106-115$.

Hamann, H., Schmidt, K. \& Simonis, S. 1989. Der Einfluss der Höhenlage auf Ei- und Gelegegrösse bei Kohlmeisen (Parus major). J. Ornithol. 130: 69-74.

Hendricks, P. 1991. Repeatability of size and shape of American Pipit eggs. Can. J. Zool. 69: 2624-2628.

Hõrak, P., Mänd, R., Ots, I. \& Leivits, A. 1995. Egg size in the Great Tit Parus major: individual, habitat and geographic differences. Ornis Fenn. 72: 97-114.

Hoyt, D.F. 1979. Practical methods of estimating volume and fresh weight of bird eggs. Auk 96: 73-77.

Järvinen, A. 1991. Proximate factors affecting egg volume in subarctic hole-nesting passerines. Ornis Fenn. 68: 99-104.

Järvinen, A. \& Pryl, M. 1989. Egg dimensions of the Great Tit Parus major in southern Finland. Ornis Fenn. 66: 69-74.

Järvinen, A. \& Väisänen, R.A. 1983. Egg size and related reproductive traits in a southern passerine Ficedula hypoleuca breeding in an extreme northern environment. Ornis Scand. 14: 253-262.

Kiziroglu, I. 1982. Brutbiologische Untersuchungen an vier Meisenarten (Parus) in der Umgebung von Ankara. J. Orn. 123: 409-423.

Lemel, J. 1989. Habitat distribution in the Great Tit Parus major in relation to reproductive success, dominance and biometry. Ornis Scand. 20: 226-233.

Mänd, R., Tilgar, V. \& Leivits, A. 2000. Reproductive response of Great Tits, Parus major, in a naturally base-poor forest habitat to calcium supplementation. Can. J. Zool. 78: 689695.

McCleery, R.H. \& Perrins, C.M. 1989. Great Tit. In Newton, I. (ed.) Lifetime Reproduction in Birds: 35-53. New York: Academic Press.

Nager, R.G. \& Zandt, H.S. 1994. Variation in egg size in Great Tits. Ardea 82: 315-328.

Nilsson, J.-A. \& Svensson, E. 1993. Causes and consequences of egg mass variation between and within blue tit clutches. J. Zool., Lond. 230: 469-481.

Nowakowski, J.K. \& Rowinski, P. 1996. Wing and body mass measurements in the Great Tit Parus major in Central Poland: errors and methods of standardization. Acta Orn. 31: 107-118.

Ojanen, M., Orell, M. \& Väisänen, R.A. 1978. Egg and clutch sizes in four passerine species in northern Finland. Ornis Fenn. 55: 60-68.

Ojanen, M., Orell, M. \& Väisänen, R.A. 1979. Role of heredity in egg size variation in the Great Tit Parus major and the Pied Flycatcher Ficedula hypoleuca. Ornis Scand. 10: 22-28.

Orell, M. 1983. Nestling growth in the Great Tit Parus major and the Willow Tit $P$. montanus. Ornis Fenn. 60: 65-82.

Orell, M. \& Ojanen, M. 1983. Timing and length of the breeding season of the Great Tit, Parus major, and the Willow Tit, P. montanus, near Oulu, northern Finland. Ardea 71: 183-198.

Pöysä, H. 1988. Feeding consequences of the dominance status in Great Tit Parus major groups. Ornis Fenn. 65: 69-75.

Sanz, J.J. 1998. Effects of geographic location and habitat on breeding parameters of Great Tits. Auk 115: 1034-1051.

Snow, D.W. 1954. Trends in geographical variation in palaearctic members of the genus Parus. Evolution 8: 19-28.

Soler, M. \& Soler, J.J. 1992. Latitudinal trends in clutch size in single brooded hole nesting bird species: a new hypothesis. Ardea 80: 293-300.

SPSS Inc. 1998. SPSS/PC+ 8.0. Chicago: SPSS Inc.

Svensson, L. 1996. Guía Para la Identificación de Los Passeriformes Europeos. Madrid: Sociedad Española de Ornitología.

Török, J. \& Csörgö, T. 1988. Breeding ecology of hole-nesting passerines in different habitats in the Pilis Mountains. Aquila 95: 67-76.

Van Noordwijk, A.J., Keizer, L.C.P., Van Balen, J.H. \& Scharloo, W. 1981. Genetic variation in egg dimensions in natural populations of Great Tit. Genetica 55: 221-232.

Verhulst, S. \& Tinbergen, J.M. 1991. Experimental evidence for a causal relationship between timing and success of reproduction in the Great Tit Parus m. major. J. Anim. Ecol. 60: 269-282.

Wiggins, D.A., Møller, A.P., Sørensen, M.F.L. \& Brand, L.A. 1998. Island biogeography and the reproductive ecology of great tits Parus major. Oecologia 115: 478-482.

Williams, T.D. 1994. Intraspecific variation in egg size and egg composition in birds: effects on offspring fitness. Biol. Rev. 68: 35-59.

Winkel, W. 1980. Über die Flügellänge von Kohl-, Blau- und Tannenmeisen (Parus major, P. caeruleus und $P$. ater) in Beziehung zu Geschlecht und Alter. Beitr. Vogelkd. 26: 213-221.

Zajac, T. 1999. Phenotypic selection on body size in the Great Tit Parus major (Niepolomice Forest, Poland). Acta Orn. 34: 219-226.

Received 21 November 2000; revision accepted 17 September 2001 
Mean \pm sd of egg dimensions and clutch size in various Great Tit populations (number of clutches in parentheses if not otherwise indicated). For each population, latitude and habitat type is also given. Breadth and length in $\mathrm{mm}$, and egg volume in $\mathrm{cm}^{3}$. SPH: sphericity; $n_{1}$ : number of clutches used in weighted regressions for egg dimensions; $n_{2}$ : number of clutches used in weighted regression for clutch size; OP: Orange plantations. References: (1) Järvinen (1991), (2) Järvinen and Pryl (1989), (3) Hõrak et al. (1995), (4) Verhulst and Tinbergen (1991), (5) Báldi and Csörgö (1993), (6) Ojanen et al. (1978), (7) Orell and Ojanen (1983), (8) J.C. Senar pers. comm., (9) Hamann et al. (1989), (10) Török and Csörgö (1988), (11) Haftorn (1985), (12) Belda et al. (1998) and E.J. Belda pers. comm., (13) Dufva (1996) and R. Dufva pers. comm. (14) Encabo et al. (2001b), (15) Kiziroglu (1982), (16) Busse [1967, cited in Hõrak et al. (1995)], (17) Sanz (1998), (18) Winkel [1970, cited in Hõrak et al. (1995)], (19) Wiggins et al. (1998), (20) Nager and Zandt (1994), (21) Divis and Skalice (1983), (22) Yaremchenko [1989, cited in Hõrak et al. (1995)].

\begin{tabular}{|c|c|c|c|c|c|c|c|c|c|}
\hline Egg volume & Breadth & Length & $\mathrm{SPH}$ & $n_{1}$ & Clutch size & $n_{2}$ & Latitude N & Habitat & Ref. \\
\hline $1.79 \pm 0.10(20)$ & $13.65 \pm 0.31(20)$ & $18.34 \pm 0.48(20)$ & $0.74^{\mathrm{b}}$ & 20 & $9.6(20)$ & 20 & $69^{\circ} 03^{\prime}$ & Deciduous & 1,2 \\
\hline $1.77 \pm 0.12(218)$ & $13.68 \pm 0.35(218)$ & $18.03 \pm 0.72(218)$ & $0.76 \pm 0.03(218)$ & 218 & $11.10 \pm 1.30(206)$ & 206 & $58^{\circ} 22^{\prime}$ & Mixed & 3 \\
\hline $1.74 \pm 0.12(317)$ & $13.60 \pm 0.35(317)$ & $17.92 \pm 0.66(317)$ & $0.76 \pm 0.03(317)$ & 317 & $8.80 \pm 1.66(297)$ & 297 & $58^{\circ} 22^{\prime}$ & Urban & 3 \\
\hline $1.73 \pm 0.13(93)$ & 13.60 & 17.90 & $0.76^{\mathrm{b}}$ & 93 & $10.21 \pm 1.27(93)$ & 93 & $58^{\circ} 09^{\prime}$ & Urban & 3 \\
\hline $1.72 \pm 0.11(13)$ & & & & 13 & $9.6 \pm 1.1(13)$ & 13 & $52^{\circ}$ & Deciduous & 4 \\
\hline $1.72 \pm 0.12(51)$ & $13.53 \pm 0.35(51)$ & $18.02 \pm 0.59(51)$ & $0.75^{\mathrm{b}}$ & 51 & $8.74 \pm 1.42(61)$ & 61 & $47^{\circ} 15^{\prime}$ & Deciduous & 5 \\
\hline $1.72 \pm 0.13(5007)^{\mathrm{a}}$ & $13.53 \pm 0.40(5007)^{\mathrm{a}}$ & $17.93 \pm 0.70(5007)^{\mathrm{a}}$ & $0.75(5007)^{\mathrm{a}}$ & 542 & $9.24(555)$ & 555 & $65^{\circ} 00^{\prime}$ & Mixed & 6,7 \\
\hline $1.72 \pm 0.12(57)$ & $13.52 \pm 0.31(57)$ & $17.91 \pm 0.67(57)$ & $0.76 \pm 0.03(57)$ & 57 & $6.47 \pm 1.00(57)$ & 57 & $41^{\circ} 27^{\prime}$ & Mixed & 8 \\
\hline $1.71 \pm 0.29(414)^{a}$ & & & & 50 & $8.30 \pm 1.31(54)$ & 54 & $47^{\circ} 30^{\prime}$ & Coniferous & 9 \\
\hline $1.70^{\mathrm{b}}$ & $13.41 \pm 0.57(168)^{a}$ & $18.03 \pm 0.76(168)^{a}$ & $0.74^{\mathrm{b}}$ & 19 & $8.83 \pm 0.74(3)^{c}$ & 29 & $47^{\circ} 43^{\prime}$ & Deciduous & 10,5 \\
\hline $1.70 \pm 0.11(36)$ & $13.55 \pm 0.35$ & $17.71 \pm 0.52(36)$ & $0.76(36)$ & 36 & $9.16 \pm 1.04(31)$ & 31 & $63^{\circ} 15^{\prime}$ & Coniferous & 11 \\
\hline $1.70 \pm 0.11(16)$ & 13.50 & 17.80 & $0.76^{b}$ & 16 & $11.69 \pm 1.78(16)$ & 16 & $58^{\circ} 09^{\prime}$ & Mixed & 3 \\
\hline $1.70 \pm 0.10(22)$ & 13.60 & 17.60 & $0.77^{\mathrm{b}}$ & 22 & $11.60 \pm 1.67(22)$ & 22 & $58^{\circ} 09^{\prime}$ & Deciduous & 3 \\
\hline $1.69 \pm 0.11(99)$ & $13.45 \pm 0.31(99)$ & $17.86 \pm 0.59(99)$ & $0.75^{\mathrm{b}}$ & 99 & $9.22(89)$ & 89 & $60^{\circ} 15^{\prime}$ & Mixed & 2 \\
\hline $1.69 \pm 0.14(20)$ & $13.44 \pm 0.34$ & $17.86 \pm 0.69(20)$ & $0.75 \pm 0.02(20)$ & 20 & $7.32 \pm 0.30(4)^{\mathrm{c}}$ & 104 & $40^{\circ} 39^{\prime}$ & Deciduous & 12 \\
\hline $1.69 \pm 0.12(73)$ & $13.42 \pm 0.35(73)$ & $17.83 \pm 0.67(73)$ & $0.75 \pm 0.03(73)$ & 73 & $8.4 \pm 1.2(73)$ & 73 & $59^{\circ} 50^{\prime}$ & Deciduous & 13 \\
\hline $1.69 \pm 0.13(521)$ & $13.34 \pm 0.37(521)$ & $18.07 \pm 0.73(521)$ & $0.74 \pm 0.03$ & 521 & $7.73 \pm 0.12(4)^{c}$ & 189 & $39^{\circ} 42^{\prime}$ & OP & 14,12 \\
\hline $1.68^{\mathrm{b}}$ & $13.35 \pm 0.56(343)^{a}$ & $17.99 \pm 2.59(343)^{\mathrm{a}}$ & $0.74^{\mathrm{b}}$ & 45 & $7.41 \pm 0.47(3)^{\mathrm{c}}$ & 193 & $40^{\circ}$ & Mixed & 15 \\
\hline $1.68^{\mathrm{b}}$ & $13.39 \pm 0.58(147)^{a}$ & $17.86 \pm 0.98(147)^{a}$ & $0.75^{b}$ & 14 & $10.15 \pm 0.49(2)^{c}$ & 20 & $47^{\circ} 43^{\prime}$ & Deciduous & 10,5 \\
\hline $1.68(1289)^{\mathrm{a}}$ & 13.49 & 17.61 & $0.77^{b}$ & 120 & $10.7(122)$ & 122 & $52^{\circ}$ & & 16 \\
\hline $1.66^{\mathrm{b}^{\mathrm{b}}}$ & $13.4^{\mathrm{b}}$ & $17.6^{\mathrm{b}}$ & $0.76^{b}$ & 8 & 8.9 & 8 & $47^{\circ} 43^{\prime}$ & Coniferous & 5 \\
\hline $1.66^{\mathrm{b}}$ & $13.37 \pm 0.44(120)^{a}$ & $17.76 \pm 0.88(120)^{a}$ & $0.75^{\mathrm{b}}$ & 13 & $9.37 \pm 1.23(3)^{c}$ & 20 & $47^{\circ} 43^{\prime}$ & Deciduous & 10,5 \\
\hline $1.66 \pm 0.15(479)^{a}$ & & & & 54 & $8.9 \pm 1.53(73)$ & 73 & $50^{\circ} 30^{\prime}$ & Coniferous & 9,17 \\
\hline $1.65 \pm 0.11(10)$ & & & & 10 & $10.8 \pm 1.1(10)$ & 10 & $52^{\circ}$ & Mixed & 4 \\
\hline $1.64 \pm 0.15(716)^{a}$ & & & & 82 & $8.7 \pm 1.57(69)$ & 69 & $50^{\circ}$ & Deciduous & 9,17 \\
\hline $1.64(42)$ & 13.30 & 17.70 & $0.75^{b}$ & 42 & 9.5 & 42 & $52^{\circ} 18^{\prime}$ & Deciduous & 18 \\
\hline $1.64 \pm 0.12(36)$ & & & & 36 & $8.4 \pm 1.2(53)$ & 53 & $56^{\circ} 43^{\prime}$ & Mixed & 19 \\
\hline $1.63 \pm 0.15(2380)^{a}$ & & & & 256 & $9.3 \pm 1.48(182)$ & 182 & $50^{\circ}$ & Deciduous & 9 \\
\hline $1.63 \pm 0.01(4)^{c}$ & & & & 93 & $8.97 \pm 1.33(93)$ & 93 & $47^{\circ} 33^{\prime}$ & Mixed & 20,3 \\
\hline $1.61 \pm 0.02(3)^{c}$ & & & & 137 & $8.11 \pm 1.45(137)$ & 137 & $47^{\circ} 33^{\prime}$ & Deciduous & 20,3 \\
\hline $1.61 \pm 0.02(4)^{c}$ & & & & 187 & $8.65 \pm 1.31(187)$ & 187 & $47^{\circ} 33^{\prime}$ & Mixed & 20,3 \\
\hline $1.61(204)^{\mathrm{a}, \mathrm{b}}$ & $13.28(204)^{\mathrm{a}}$ & $17.46(204)^{\mathrm{a}}$ & $0.76^{b}$ & 22 & $9.37 \pm 1.87(59)$ & 59 & $49^{\circ}$ & & 21 \\
\hline $1.60 \pm 0.14(1993)^{a}$ & & & & 240 & $8.3 \pm 1.54(227)$ & 227 & $50^{\circ}$ & Mixed & 9,17 \\
\hline $1.60 \pm 0.14(1816)^{a}$ & & & & 206 & $8.8 \pm 1.46(183)$ & 183 & $50^{\circ}$ & Deciduous & 9,17 \\
\hline $1.59(569)^{\mathrm{a}}$ & 13.2 & 17.40 & $0.76^{b}$ & 49 & 11.5 & 49 & $50^{\circ}$ & & 22 \\
\hline $1.58 \pm 0.13(44)$ & & & & 44 & $9.6 \pm 1.1(30)$ & 30 & $56^{\circ} 11^{\prime}$ & Mixed & 19 \\
\hline $1.56 \pm 0.11(43)$ & & & & 43 & $9.0 \pm 1.1(53)$ & 53 & $57^{\circ} 17^{\prime}$ & Mixed & 19 \\
\hline $1.52 \pm 0.15(497)^{\mathrm{a}}$ & & & & 65 & $7.6 \pm 1.40(289)$ & 289 & $52^{\circ}$ & Urban & 9,17 \\
\hline
\end{tabular}

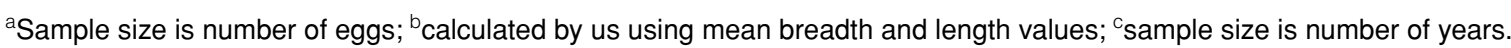




\section{APPENDIX 2}

Mean wing length of female Great Tits at different latitudes.

\begin{tabular}{|c|c|c|}
\hline Mean wing length $\pm \mathrm{sd}(n)$ & Latitude north & Source \\
\hline $76.46 \pm 1.43(97)$ & $65^{\circ} 00^{\prime}$ & Orell (1983) \\
\hline $75.7 \pm 1.12(19)$ & $59^{\circ} 50^{\prime}$ & Alatalo et al. (1984) \\
\hline $75.68 \pm 1.6(131)$ & $52^{\circ}$ & Winkel (1980) \\
\hline $75.57 \pm 1.40(415)$ & $58^{\circ} 22^{\prime}$ & P. Hõrak pers. comm. \\
\hline $75.47 \pm 0.17(73)$ & $59^{\circ} 45^{\prime}$ & Haftorn (1976) \\
\hline $74.7 \pm 1.8(7)$ & $61^{\circ} 35^{\prime}$ & Pöysä (1988) \\
\hline $74.47 \pm 1.73(670)$ & $58^{\circ} 22^{\prime}$ & P. Hõrak pers. comm. \\
\hline $74.39 \pm 1.57(61)$ & $58^{\circ} 08^{\prime}$ & Mänd et al. (2000) \\
\hline $74.3 \pm 1.9(70)$ & $60^{\circ} 15^{\prime}$ & Järvinen and Pryl (1989) \\
\hline $74.23 \pm 1.95(44)$ & $47^{\circ} 15^{\prime}$ & Báldi and Csörgö (1993) \\
\hline $74.2 \pm 1.45(33)$ & $58^{\circ} 05^{\prime}$ & Lemel (1989) \\
\hline $74.1 \pm 0.57(16)$ & $50^{\circ} 58^{\prime}$ & Zajac (1999) \\
\hline $74.0 \pm 0.9(6)$ & $56^{\circ} 11^{\prime}$ & Wiggins et al. (1998) \\
\hline $73.98 \pm 1.55(20)$ & $40^{\circ} 39^{\prime}$ & E.J. Belda pers. comm. \\
\hline $73.9 \pm 1.28(21)$ & $58^{\circ} 05^{\prime}$ & Lemel (1989) \\
\hline $73.8 \pm 1.3(48)$ & $52^{\circ} 16^{\prime}$ & Nowakowski and Rowinski (1996) \\
\hline $73.7 \pm 0.43(10)$ & $55^{\circ} 47^{\prime}$ & Ebenman (1986) \\
\hline $73.5 \pm 1.4(14)$ & $56^{\circ} 43^{\prime}$ & Wiggins et al. (1998) \\
\hline $73.25 \pm 1.63(56)$ & $41^{\circ} 27^{\prime}$ & J.C. Senar pers. comm. \\
\hline $73.25 \pm 0.28(5)$ & $55^{\circ} 23^{\prime}$ & Ebenman (1986) \\
\hline $72.99 \pm 3.11(304)$ & $51^{\circ} 40^{\prime}$ & McCleery and Perrins (1989) \\
\hline $72.8 \pm 2.41(34)$ & $51^{\circ} 00^{\prime}$ & Flegg and Cox (1977) \\
\hline $72.7 \pm 0.44(10)$ & $55^{\circ} 38^{\prime}$ & Ebenman (1986) \\
\hline $72.4 \pm 1.98(8)$ & $41^{\circ} 56^{\prime}$ & Fraticelli and Ruvolo (1985) \\
\hline $72.27(38)$ & $51^{\circ} 11^{\prime}$ & Dhondt and Schillemans (1983) \\
\hline $72.23 \pm 0.20(73)$ & $59^{\circ} 50^{\prime}$ & R. Dufva pers. comm. \\
\hline $71.3 \pm 1.77(46)$ & $40^{\circ} 45^{\prime}$ & Fusco et al. (1991) \\
\hline $69.80 \pm 1.82(248)$ & $39^{\circ} 42^{\prime}$ & This study \\
\hline
\end{tabular}

